\title{
EDUCAÇÃO ESPECIAL NO CONTEXTO DE PANDEMIA: reflexões sobre políticas educacionais
}

\author{
Alessandra Andrade Cardoso \\ Gustavo Diniz de Mesquita Taveira \\ Guilherme Pereira Stribel
}

\section{Resumo}

A pandemia de coronavírus (Covid-19) trouxe mudanças no cenário econômico, político, social e educacional do mundo. As escolas de muitos países estão fechadas, algumas adotando aulas remotas e/ou educação à distância. Com isso, grupos que já apresentavam graus de vulnerabilidade, como o caso dos alunos e alunas com deficiência, ficam ainda mais cerceados do direito à educação escolar, principalmente na realidade brasileira. Nessa direção, esse trabalho visa fomentar discussão entre a evolução histórica dos processos de inclusão de tais alunos e as consequências ocasionadas pela necessidade do isolamento em decorrência da pandemia, a fim de evidenciar a relevância e urgência da consolidação de políticas públicas educacionais de inclusão. Para isso realizamos uma análise documental a partir de um panorama histórico das políticas públicas educacionais voltadas às pessoas com deficiência no Brasil.

Palavras-chave: inclusão; políticas públicas; coronavírus.

\section{SPECIAL EDUCATION IN THE PANDEMIC CONTEXTT:} reflections on educational policies

\begin{abstract}
The coronavirus pandemic (Covid-19) has brought about changes in the world's economic, political, social and educational landscape. Schools in many countries are closed, some adopting remote classes and / or distance education. As a result, groups that already had degrees of vulnerability, such as students with disabilities, are further restricted by the right to school education, especially in the Brazilian context. In this direction, this work aims to foster discussion between the historical evolution of the inclusion processes of such students and the consequences caused by the need for isolation due to the pandemic, in order to highlight the relevance and urgency of the consolidation of public educational policies for inclusion. For this, we performed a documentary analysis based on a historical overview of public educational policies aimed at people with disabilities in Brazil.
\end{abstract}

Keywords: inclusion; public policy; coronavirus.

\section{EDUCACIÓN ESPECIAL EN EL CONTEXTO PANDÉMICO: reflexiones sobre políticas educativas}

\section{Resumen}

La pandemia de coronavirus (Covid-19) ha provocado cambios en el panorama económico, político, social y educativo del mundo. Las escuelas en muchos países están cerradas, algunas adoptan clases remotas y / o educación a distancia. Como resultado, los grupos que ya tenían grados de vulnerabilidad, como los estudiantes con discapacidades, están aún más restringidos por el derecho a la educación escolar, especialmente en el contexto brasileño. En esta dirección, este trabajo tiene como objetivo fomentar la 
discusión entre la evolución histórica de los procesos de inclusión de dichos estudiantes y las consecuencias causadas por la necesidad de aislamiento debido a la pandemia, con el fin de resaltar la relevancia y la urgencia de la consolidación de las políticas educativas públicas para la inclusión. Para ello, realizamos un análisis documental basado en una visión histórica de las políticas educativas públicas dirigidas a personas con discapacidad en Brasil.

Palabras clave: inclusión; políticas públicas; coronavirus.

\section{CONTEXTO DA PANDEMIA}

Desde o final do ano de 2019, o mundo observa a ascensão gradativa e exponencial do que viria a se tornar uma pandemia. A Coronavirus desease - (Covid-19), popularmente chamada por coronavírus, pode causar dor de garganta, tosse, febre e, em casos graves, dificuldade de respirar e pneumonia, o que pode levar a óbito (CHEN, 2020). O vírus se instala nas vias aéreas e é transmitido, de humano para humano, através de gotículas de saliva que são expelidas pela boca da pessoa contaminada (XINHUA, 2020). Há indícios que o vírus começou a ser propagado em território chinês, e, por ter alta transmissibilidade, avançou celeremente por todo o globo (HUANG, 2020).

Infelizmente, a quantidade de óbitos causada pela doença já ultrapassa a casa dos milhares no mundo. Países como Itália, Espanha e Estados Unidos foram os mais afetados, onde o sistema de saúde já não consegue suportar a quantidade de pacientes que precisam de Unidades de Terapia Intensiva (UTI) e respiradouros (WHO, 2020). Dentre as recomendações da Organização Mundial da Saúde se destacam a testagem de toda a população para o novo coronavírus e o estado de isolamento social para toda a população mundial e quarentena para as pessoas que apresentarem alguns dos sintomas da doença, a fim de suprimir o contágio e achatar a curva de transmissão do vírus, fazendo com que as autoridades, os sistemas de saúde e os cientistas ganhem tempo na luta contra a doença.

Apesar de ser uma recomendação de todas as entidades de saúde nacionais e internacionais (incluindo o Ministério da Saúde brasileiro), o isolamento social é amplamente criticado por alguns setores conservadores da política e da economia brasileira (empresários e líderes religiosos atrelados à direita conservadora), principalmente pelo atual presidente do Brasil, Jair Bolsonaro. Em um de seus pronunciamentos em rede nacional, sugeriu a ideia de "isolamento vertical", na qual os indivíduos do grupo de risco (idosos, doentes crônicos ou que possuem algum tipo de morbidade) se mantivessem isolados enquanto os jovens e adultos pudessem voltar a ocupar os postos de trabalho, fazendo com que a economia não fosse tão prejudicada. Pontuamos aqui que tal estratégia já foi aplicada inicialmente em outros países e culminou em problemas gravíssimos e alto número de mortos. O prefeito de Milão, na Itália, chegou a lançar a campanha \#Milannosiferma (Milão não pode parar), algumas semanas depois veio a público pedir desculpas à cidade que contabiliza um dos maiores números de óbitos no mundo pelo coronavírus. Essa campanha chegou a servir de molde (beirando ao plágio) pelo governo brasileiro, com o nome \#OBrasilNãoPodeParar, que custou $\mathrm{R} \$ 4,8$ milhões. A Justiça Federal impediu sua veiculação na televisão e no rádio, mas o vídeo circulou nas redes sociais; não há explicações sobre o gasto desnecessário com a campanha.

Mesmo com os embates entre os diferentes campos político-econômicos, grande parte dos brasileiros segue em estado de isolamento social. Servidores públicos, trabalhadores assalariados, autônomos, pequenos empresários e professores são exemplos de profissionais que estão em suas casas desde o dia 16/03/2020. Com isso, reacende o debate sobre o ensino remoto e a Educação à Distância (EaD). Muitas escolas e universidades estão adotando (ao que indicam, 
emergencialmente) essa modalidade com o intuito de não atrasar o calendário acadêmico e garantirem o cumprimento do conteúdo a seus alunos.

Como pontua Junqueira,

Não se pode confundir educação a distância $(\mathrm{EaD})$ com atividade remota pela internet em situação de crise grave. EaD é toda uma concepção didática e de estudo e aprendizagem que envolve estrutura, conteúdos, formação e que abrange desde o desenho didático inicial adequado às características da área do conhecimento específica até às avaliações da aprendizagem discente, executada por equipe multidisciplinar treinada. $\mathrm{E}$ existem diversos tipos, diversas concepções de EaD. Atividade remota é fazer alguma atividade temporária via internet, em situações precárias e emergenciais, para tentar reduzir danos de aprendizagem a partir de um sistema de ensino originalmente presencial. (JUNQUEIRA, 2020)

E proposta de ensino remoto não deve ser tomada como sinônimo de $\mathrm{EaD}$, uma vez que a primeira parte da ideia de adaptação de atividades ou práticas presenciais a uma série de possibilidades virtuais, em vias de permitir o ensino-aprendizagem quando a presencialidade não é viável. Já a EaD compreende uma modalidade educacional com estruturas bem definidas, que pode ter relação com a presencialidade, mas não de forma substitutiva.

Nesse cenário de isolamento social e com a suspensão das aulas, recorreu-se ao ensino remoto, e no Estado do Rio de Janeiro ele é uma ação forte da Secretaria Estadual de Educação que leva professores e estudantes a utilizarem ferramentas tecnológicas para darem continuidade ao processo de ensino- aprendizagem, porém o que notoriamente se percebe é que na perspectiva de uma escola inclusiva essas modalidades de ensino não atenderão a maioria dos alunos públicoalvo da educação especial, também não atenderá a uma parcela dos demais estudantes que necessitam de maneira muito dependente da mediação e intervenção direta dos professores considerando suas necessidades e há ainda aqueles que não têm acesso às ferramentas necessárias ao ensino remoto e de certa forma essas minorias estão excluídas.

Com intuito de fomentar essa discussão no meio acadêmico, este ensaio objetiva evidenciar a necessidade de políticas públicas eficazes e democráticas que atendam efetivamente a educação especial em sua totalidade, bem como a e as consequências ocasionadas pela necessidade do isolamento em decorrência da pandemia causada pela Covid-19. Importante destacar também que as transformações sociais, como as que estamos vivenciando, se dão em meio às lutas diárias por uma sociedade mais justa e equitativa, e a educação inclusiva tem papel fundamental nessa luta.

Dessa forma estamos diante de um trabalho árduo e desafiador, que disputa com direções políticas que vão muitas vezes à contramão dos processos de inclusão. Educação para inclusão é um ato político, como afirma Damasceno,

A questão da educação inclusiva é política. Como dissociar a educação da política? Lembrando Paulo Freire, ao afirmar que "A educação é um ato político". Portanto, não podemos negar que a inclusão escolar traz consigo interesses que se velam nos meandros dos discursos, das políticas afirmativas, nos textos legais, entre outros. (DAMASCENO, 2006, p. 178).

Considerando os muitos desafios nas escolas em âmbito nacional, nos diversos níveis de ensino e o histórico da Educação Especial na perspectiva inclusiva, temos um desafio ainda maior 
DOI: $10.12957 /$ teias.\%Y.50005

em tempos de pandemia. De acordo Mendes e Bastos (2016) que destacam a inclusão como tema gerador de muitos debates:

[...] o processo de inclusão de pessoas com deficiências no ensino comum é algo recente e vem sendo apresentado como assunto de grandes debates em discussões educacionais, tanto em relação às políticas de atendimento às necessidades, como no diálogo de educadores em relação aos atendimentos às necessidades em sala de aula. (MENDES, BASTOS, 2016, p. 2).

É preciso então, debater o tema inclusão, quando mais uma vez alunos com deficiência se tornam excluídos (ainda que forçosamente pelas circunstâncias). Para Moreira e Couto (2016), a inclusão ocorre não somente pelo cumprimento de decretos e leis, é essencial que haja um esforço da comunidade acadêmica e sociedade de modo geral para uma inclusão que, mesmo não sendo a ideal, seja ao menos satisfatória (apud ROSA, et al., 2020, p. 4).

Logo, utilizaremos como metodologia a análise documental (Richardson, 1999) de políticas públicas voltadas para pessoas com deficiência e revisão da literatura pertinente. Com isso, apresentaremos neste ensaio uma linha temporal das leis e documentos internacionais que visam garantir a educação inclusiva no Brasil e no mundo.

\section{LINHA TEMPORAL DAS POLÍTICAS VOLTADAS À EDUCAÇÃO ESPECIAL}

É importante notar que, quando fala-se sobre política, referimo-nos às ideias que circulam socialmente e que orientam diferentes instâncias da vida humana, desde ações supra-estatais até do cotidiano, através da produção e disputa por significação, considerando que a política apresenta-se tanto como discurso quanto como texto (BALL, 1994). Neste sentido, a linha temporal apresentada a seguir salienta marcos, de diferentes naturezas, que balizam, direta ou indiretamente, as políticas sobre a educação especial.

Várias leis e documentos internacionais garantem o acesso e a permanência de todos sem distinção no sistema educacional, seguem algumas das mais importantes:

1988 - CONSTITUIÇÃO DA REPÚBLICA - Prevê o pleno desenvolvimento dos cidadãos, sem preconceito de origem, raça, sexo, cor, idade e quaisquer outras formas de discriminação; garante o direito à escola para todos; e coloca como princípio para a Educação o "acesso aos níveis mais elevados do ensino, da pesquisa e da criação artística, segundo a capacidade de cada um";

1989 - LEI No 7.853/89 - define como crime recusar, suspender, adiar, cancelar ou extinguir a matrícula de um estudante por causa de sua deficiência, em qualquer curso ou nível de ensino, seja ele público ou privado;

1990 - ESTATUTO DA CRIANÇA E DO ADOLESCENTE (ECA) - garante o direito à igualdade de condições para o acesso e a permanência na escola, sendo o Ensino Fundamental obrigatório e gratuito (também aos que não tiveram acesso na idade própria); o respeito dos educadores; e atendimento educacional especializado, preferencialmente na rede regular;

1994 - DECLARAÇÃO DE SALAMANCA - O texto, que não tem efeito de lei, diz que também devem receber atendimento especializado crianças excluídas da escola por motivos como trabalho infantil e abuso sexual. As que têm deficiências graves devem ser atendidas no mesmo ambiente de ensino que todas as demais; 
1996 - LEI DE DIRETRIZES E BASES DA EDUCAÇÃO NACIONAL (LDB) - o texto diz que o atendimento especializado pode ocorrer em classes ou em escolas especiais, quando não for possível oferecê-lo na escola comum;

2000 - LEIS No $10.048 \mathrm{E} \mathrm{N}^{\circ} 10.098$ - a primeira garante atendimento prioritário de pessoas com deficiência nos locais públicos. A segunda estabelece normas sobre acessibilidade física e define como barreira obstáculos nas vias e no interior dos edifícios, nos meios de transporte e tudo o que dificulte a expressão ou o recebimento de mensagens por intermédio dos meios de comunicação, sejam ou não de massa;

2001 - DIRETRIZES NACIONAIS PARA A EDUCAÇÃO ESPECIAL NA EDUCAÇÃO BÁSICA - explicitam as normas relativas ao atendimento dos (as) alunos (as) com "necessidades educacionais especiais" nas escolas regulares;

2007 - PROGRAMA DE ACOMPANHAMENTO E MONITORAMENTO DO ACESSO E PERMANÊNCIA NA ESCOLA DAS PESSOAS COM DEFICIÊNCIA BENEFICIÁRIAS DO BENEFÍCIO DE PRESTAÇÃO CONTINUADA DA ASSISTÊNCIA SOCIAL - Programa BPC - Portaria Normativa Interministerial n. 18, de 24 de abril de 2007, instituiu o Programa de Acompanhamento e Monitoramento do Acesso e Permanência na Escola das Pessoas com Deficiência Beneficiárias do Benefício de Prestação Continuada da Assistência Social - Programa BPC na escola, através do cruzamento anual entre os dados do EducaCenso e do cadastro administrativo do Ministério da Previdência;

2007 - PLANO DE DESENVOLVIMENTO DA EDUCAÇÃO (PDE) - política do governo federal. Tinha por objetivo a melhoria da Educação Básica, e nesse sentido agregou 30 ações que incidiram sobre os mais variados aspectos da educação em seus diversos níveis e modalidades que previa ampliação de números de salas e equipamentos para a Educação Especial e capacitação de professores para o atendimento educacional especializado;

2008 - POLÍTICA NACIONAL DE EDUCAÇÃO ESPECIAL NA PERSPECTIVA DA EDUCAÇÃO INCLUSIVA - resultado do amplo processo de discussão promovido pelo Grupo de Trabalho - Portaria Ministerial No 555/2007, constituído por professores pesquisadores da área da educação especial, sob a coordenação da Secretaria de Educação Especial - SEESP/MEC;

2015 - LEI BRASILEIRA DE INCLUSÃO No 13. 146, DE 06 DE JULHO DE 2015 estabelece direitos fundamentais das pessoas com deficiência, como educação, transporte e saúde, acesso à informação e comunicação e do uso de tecnologias assistivas.

É importante reconhecer que políticas públicas têm sido desenvolvidas no país, nos últimos anos, para a educação especial na perspectiva da inclusão. $O$ governo federal vem apresentando políticas, planos, programas e ações nessa perspectiva. Existem avanços quanto à formação de profissionais, instalações e recursos, mas ainda é preciso avançar muito, e é urgente. De acordo, Mendes (2010):

[...] a despeito das evoluções no discurso, na atualidade constata-se que, para uma estimativa de cerca de seis milhões de crianças e jovens com necessidades educacionais especiais, cerca de 800 mil matrículas, considerando o conjunto de todos os tipos de recursos disponíveis, ou seja, desde os matriculados em escolas especiais até os que estão nas escolas comuns. A grande maioria dos alunos com necessidades educacionais especiais está fora de qualquer tipo de escola (MENDES, 2010, p. 106).

Reconhecidamente, há numerosas legislações que garantem direitos às pessoas com deficiência. Todavia, não se desdobram em políticas públicas educacionais suficientes em 
abrangência e em eficiência para de fato garantir a inclusão escolar, um exemplo, é que não se tinha um plano de contingência educacional para situações como a que estamos vivenciando com o coronavírus. Bonetti (2006) traz contribuições com a compreensão de que as políticas públicas são ações que nascem do contexto social, que perpassam pela esfera estatal como uma decisão de intervenção pública numa realidade social, seja para fazer investimentos ou para regulamentação administrativa, por resultado da guerra de forças entre economia e política, entre as classes sociais e outras organizações. Talvez a partir dessa experiência possamos também repensar a importância e a relevância de atos políticos educacionais que se tornem de fato universais respeitando as individualidades, uma vez que já estão previstos na meta 4 do Plano Nacional de Educação.

O Plano Nacional de Educação (PNE) determina diretrizes, metas e estratégias para a política educacional no período de 2014 a 2024. Em sua Meta 4, busca universalizar o atendimento escolar aos estudantes com deficiência, transtornos globais do desenvolvimento e altas habilidades ou superdotação, de preferência na rede regular de ensino. Presumindo que as demais metas do PNE também alcancem a população com deficiência é urgente que, para além da universalização, a garantia na qualidade do atendimento, inclusão e a aprendizagem efetivamente aconteçam.

Com a recente homologação da Base Nacional Comum Curricular (BNCC) em 14 de dezembro de 2018, pelo então Ministro da Educação, Rossieli Soares, estados e municípios deverão (re)elaborar seus currículos, atendendo ao documento que é de caráter normativo. Nesse cenário cresce a preocupação com essa adaptação curricular refletida nas práticas educativas inclusivas que, além de atender à BNCC, que define o conjunto de aprendizagens essenciais que todos os alunos devem desenvolver ao longo das etapas e modalidades da Educação Básica (é o que pretende o documento sem garantias de execução), precisa respeitar a identidade local e demanda de políticas públicas educacionais que atendam à educação especial sob perspectiva da inclusão.

Em 2008, foi publicada a Política Nacional de Educação Especial na Perspectiva da Educação Inclusiva (PNEEPEI) (BRASIL, 2008), que tem dentre outras garantias a de assegurar a inclusão escolar de alunos com deficiência, transtornos globais do desenvolvimento e altas habilidades/superdotação; a oferta do atendimento educacional especializado; formação de professores para os atendimentos educacionais especializados e demais profissionais da educação para a inclusão; acessibilidade arquitetônica, nos transportes, nos mobiliários, nas comunicações e informação; e articulação intersetorial na implementação das políticas públicas.

No entanto, é válido salientar que a PNEEPEI é resultado de grupo de trabalho nomeado por Portaria Ministerial em 2007 cujo acesso ficou disponibilizado para conhecimento de leitores e eventuais sugestões sem o caráter de consulta pública, e que mais de 10 anos se passaram, e nesse ínterim a Secretaria de Educação Especial no MEC foi extinta e absorvida pela Secretaria de Educação Continuada, Alfabetização, Diversidade, Inclusão — SECADI.

Democratizar a Educação para o público-alvo da Educação Especial em tempos de flexibilidade nos meios econômico e político implica em mudanças no espaço escolar, na disposição dos atores sociais, no objeto de intervenção pública, reverberando em rearranjos de acordo com a nova correlação de forças que pode, a partir daí, se construir de fato uma escola inclusiva. Assim, percebe-se que nessa luta constante por espaços e por efetivação de novas políticas educacionais, a realidade de enfrentamento ao coronavírus apresenta-se como um momento de oportunidades de deslocamentos políticos nos campos educacional, econômico, político e social.

COMO FICAM AS PESSOAS COM DEFICIÊNCIA PÓS-PANDEMIA COVID-19 NAS REDES DE ENSINO? 
Como ponto de partida dessa reflexão, estamos pensando no pós-pandemia para os estudantes com deficiência inseridos na rede escolar, para quem períodos de adaptação escolar são quase sempre difíceis e por vezes dolorosos, em alguns casos sem êxito. Logo, considerar que na grande maioria dos casos, os estudantes com deficiência não estão apenas afastados de atividades escolares, que são, por vezes, o único local de socialização desses alunos além do núcleo familiar, mas estão também afastados de suas terapias, de suas consultas, fisioterapias etc, o isolamento para a maioria dos estudantes com deficiência significa também estar afastado de seus tratamentos/ acompanhamentos, esse fator por si só já nos remete a um maior grau de dificuldade no período pós- pandemia.

Vivemos um tempo de transformação global, a Covid-19 alterou o cotidiano em quase todos os lugares, mexeu profundamente com a economia e com o modo de vida das pessoas. Serão necessárias adaptações nos espaços e nos recursos, mas principalmente uma mudança de atitude, que reflita a concepção de convivência universal, não só na infraestrutura das escolas, mas também e fundamentalmente no desenvolvimento de práticas de ensino-aprendizagem e nas relações humanas.

$\mathrm{Na}$ perspectiva da educação inclusiva, o foco na adaptação não deverá ser nunca na deficiência e sim nos espaços, nos recursos que deverão ser acessíveis, nas potencialidades dos estudantes e corresponder às especificidades de cada aluno. Ou seja, práticas pedagógicas concebidas em atender todos os alunos, independente de suas condições ou especificidades.

Acreditamos que o isolamento social ressalta o aspecto assistencialista da educação especial, enquanto política de ocupação de pessoas em um espaço determinado (escola), uma vez que suas características são concebidas como diferenças que não se adequam a espaços fora do eixo casaescola. Evidentemente, dada a situação de isolamento social, todos, inclusive pessoas com deficiência e com necessidades específicas, ficam em casa, sendo esta uma instituição/aparelho social que pode não contar com o aparato necessário para manutenção de atividades físicas e pedagógicas. Desse modo, apesar de ser necessário o isolamento, ele pode ressaltar que, mesmo precariamente, a escola continua sendo um baluarte de inclusão em uma sociedade excludente.

\section{REFERÊNCIAS}

BALL, Stephen J. Education reform - a critical and post-structural approach. Buckinghan: Open University, 1994.

BONETI, L. W. Políticas Públicas por Dentro. Ijuí: Editora Unijuí, 2006.

BRASIL. Constituição Federal. Brasília; Imprensa Oficial, 1988.

BRASIL. Estatuto da Criança e do Adolescente. Câmara dos Deputados, Lei no 8.069, de 13 de julho de 1990. DOU de 16/07/1990 - ECA. Brasilia, DF,1990.

BRASIL. Lei Brasileira de Inclusão. Lei 13.146 de 6 de julho de 2015.

BRASIL. Lei de Diretrizes e Bases da Educação Básica: Lei 9.394 de 20 de dezembro de 1996.

BRASIL. Legislação Brasileira sobre pessoa com Deficiência: Lei 7.853 de 24 de outubro de 1989.

BRASIL. Lei n. 10.048, de 8 de novembro de 2000. Planalto, Brasília, DF, 2000.

BRASIL. Lei n. 10.098, de 19 de dezembro de 2000. Câmara dos Deputados, Brasília, DF, 2000.

BRASIL. Ministério da Educação. Diretrizes Nacionais para a Educação Especial na Educação Básica. Secretaria de Educação Especial- MEC; SEESP, 2001. 
DOI: $10.12957 /$ teias. $\%$ Y.50005

BRASIL. Ministério da Educação. O Plano de Desenvolvimento da Educação: razões, princípios e programas. Brasília, DF: MEC, 2007.

BRASIL. Ministério da Educação. Plano Nacional da Educaşão. MEC; 2014.

BRASIL. Ministério da Educação. Política Nacional de Educação Especial na perspectiva da Educaşão Inclusiva. MEC; SEEP; 2008.

BRASIL. Portaria Normativa Interministerial n. 18. Programa BPC na escola. Brasília: MEC, 2007.

CHEN W., PETER H. W.; HAYDEN F. G.; GAO G. F. A novel coronavirus outbreak of global health concern. The Lancet. 395(10223):470-473. 2020.

Conferência Mundial sobre Necessidades Educativas Especiais: Acesso e Qualidade. Declaração de Salamanca e Enquadramento da Acção. Salamanca. UNESCO, 1994.

DAMASCENO, A. R. A formação de professores e os desafios para a educação inclusiva: as experiências da Escola Municipal Leônidas Sobrino Pôrto. Niterói: 10/04/2006. 194 f., 3 cm. Dissertação (Mestrado em Educação) - Universidade Federal Fluminense, 2006.

HUANG C. et al. Clinical features of patients infected with 2019 novel coronavirus in Wuban. Lancet, China. 395: 497-506, mar., 2020.

JUNQUEIRA, Eduardo. Não se pode confundir educação [...]. O Povo, 27 mar. 2020. Disponível em https://mais.opovo.com.br/jornal/opiniao/2020/03/27/eduardo-junqueira-atividade-escolarremota-nao-e-ead.html. Acesso em 08 abr. 2020.

MENDES, E. G. Breve Histórico da Educação Especial no Brasil. Revista Educación y Pedagogía, v. 22, núm. 57, mayo-ago., 2010. p. 106

MENDES, Hernestina da Silva Faiux; BASTOS, Camen Célia Barradas Correia. Um estudo sobre a realidade da inclusão de pessoas com deficiência na Educação Superior no Paraná. Revista Educação Especial. Santa Maria, n. 54, jan. 2016. Disponível em https://periodicos.ufsm.br/educacaoespecial/article/view/17215. Acesso em 13 ago. 2020.

RICHARDSON, R. J. Pesquisa social: métodos e técnicas. São Paulo: Atlas, 1999.

ROSA, Carla Marielly; VIÇOSA, Cátia Silene Carrazoni Lopes; FOLMER, Vanderley; SALGUEIRO, Andréia Caroline Fernandes. Inclusão no Ensino Superior e o uso de Tecnologias Assistivas: uma avaliação com base nas percepções de discentes de licenciatura, Revista Educação Especial, Santa Maria, v. 33, 2020. Disponível em https://periodicos.ufsm.br/educacaoespecial. Acesso em 13 ago 2020.

WORLD HEALTH ORGANIZATION. Coronavirus disease 2019 (COVID-19): Situation Report 78, 2020.

XINHUA. China's CDC detects a large number of new coronaviruses in the South China seafood market in Wuhan, 2020. Disponível em https://www.xinhuanet.com/2020-01/27/c 1125504355.htm. Acesso em 20 fev. 2020.

Submetido em abril de 2020 Aprovado em agosto de 2020

\section{Informações dos autores}

Alessandra Andrade Cardoso 
DOI: $10.12957 /$ teias.\%Y.50005

Secretaria Municipal de Educação, Esporte e Lazer de Mangaratiba/Laboratório de Estudos e Pesquisa em Educação, Diversidade e Inclusão (LEPEDI)/Universidade Federal Rural do Rio de Janeiro

E-mail: alessandrandrade1000@gmail.com

ORCID: https://orcid.org/0000-0002-4798-7426

Link Lattes: http://lattes.cnpq.br/9044478148931109

Gustavo Diniz de Mesquita Taveira

Secretaria Municipal de Educação, Esporte e Lazer de Mangaratiba/Instituto de Bioquímica Médica Leopoldo De Meis, Universidade Federal do Rio de Janeiro

E-mail: taveiragdm@gmail.com

ORCID: https://orcid.org/0000-0002-0959-3143

Link Lattes: http://lattes.cnpq.br/7884855831458741

Guilherme Pereira Stribel

Universidade Estácio de Sá (UNESA)

E-mail: stribelgp@gmail.com

ORCID: https://orcid.org/0000-0002-5633-4670

Link Lattes: http://lattes.cnpq.br/8791541644386743 